\title{
VIVÊNCIAS E CONVIVÊNCIAS DE LAZER NO BAIRRO DE FELIPE
} CAMARÃO

\author{
Henrique José Concentino Fernandes ${ }^{1}$ \\ Maria de Lourdes da Silva Rocha ${ }^{2}$ \\ Letícia Rozana Silva do Nascimento ${ }^{3}$ \\ Sônia Cristina Ferreira Maia ${ }^{4}$
}

\author{
${ }^{1}$ Graduando do Curso Superior de Lazer e Qualidade de Vida do CEFET/RN \\ ${ }^{2}$ Graduanda do Curso Superior de Lazer e Qualidade de Vida do CEFET/RN. : lourdesil@yahoo.com.br \\ ${ }^{3}$ Graduanda do Curso Superior de Lazer e Qualidade de Vida do CEFET/RN. \\ leti18br@cefetrn.br \\ ${ }^{4}$ Professora do CEFET/RN. Mestre em Engenharia da Produção. Sonia@cefetrn.br
}

\section{RESUMO}

Este estudo é fruto de um esforço coletivo, dos alunos do Curso Superior de lazer e Qualidade de Vida do Centro Federal de Educação Tecnológica do Rio Grande do Norte CEFET/RN, no mapeamento dos equipamentos de lazer, sua organização espacial e inserção urbana, na forma de um diagnóstico da infra-estrutura urbana destinada ao lazer no Bairro de Felipe Camarão, na periferia da cidade de Natal, Rio Grande do Norte. Espera-se com esta pesquisa enriquecer os conhecimentos a respeito dos equipamentos de lazer de nossa cidade, como também fornecer dados concretos sobre a situação atual destes equipamentos, favorecendo o desenvolvimento de políticas públicas e mobilizações sociais capazes de reverter este quadro desolador de descaso e abandono.

Palavras-chave: Equipamentos Públicos; Lazer; Urbanismo.

\section{EXPERIENCES OF LEISURE IN THE QUARTER OF FELIPE CAMARÃO}

\begin{abstract}
This study results of a collective study developed by students at the university course on Leisure and Life Quality at the Federal Center of Technological Education in Rio Grande do Norte - CEFET-RN, related to the mapping of leisure equipment, its spatial organization and urban insertion, shaped like a diagnosis of urban structure destined to leisure at Felipe Camarão District, in the outskirts of Natal city, Rio Grande do Norte. Through this research, we expect to enlarge knowledge about the leisure equipment which exists in the city, as well as to provide data about the real situation of the equipment, favoring the development of public programs, and social mobilizations able to revert this grievous scenery of abandon and lack of maintenance.
\end{abstract}

Keywords: Public equipment; Leisure; Urbanism. 


\section{VIVÊNCIAS E CONVIVÊNCIAS DE LAZER NO BAIRRO DE FELIPE CAMARÃO}

\section{LAZER E URBANISMO}

Nas cidades se concentram grandes aglomerações humanas, produzindo uma cultura urbana, que consiste de formas de convivências, relações e construções sociais decorrentes da vida concentrada em espaços comuns. Decorrem daí, vários problemas como o transporte, saneamento, abastecimento de água e espaços para promoção de atividades de lazer.

Apesar das grandes cidades existirem há pouco tempo na cultura humana, pensar o urbanismo não é algo novo. Existem vários conceitos, abrangendo um conjunto cada vez mais diversificado de questões que nem se sonhava que viessem a surgir. Em sua existência, o urbanismo consiste nas relações entre espaço da cidade e a sociedade que nela vive. Com isso, a evolução do urbanismo ocorre de acordo com as transformações do espaço e da sociedade.

O desenvolvimento do espaço urbano teve um impacto enorme não apenas nos hábitos e formas de comportamento, mas também na forma de pensar e de sentir dos habitantes das cidades. Este espaço é permanentemente reestruturado, onde os moradores decidem construir e modificar sem levar em consideração aspectos ambientais, espaços comunitários e de infra-estrutura. Buscando organizar e ordenar a utilização destes espaços, cada vez mais, temos percebido demandas pela adoção de políticas públicas e ações comunitárias, buscando assim, planejar a ocupação das cidades, primando pelo atendimento das condições básicas de infra-estrutura, lazer e moradia, contribuindo para a efetivação de espaços capazes de promover a qualidade de vida.

Na contramão deste processo, temos a globalização neoliberal, a indústria cultural da mídia high-tech e do entretenimento, que promovem a cultura shopping center e fast food, retratam a redução dos espaços sociais e os interesses de mercado, de segregação e culto à violência, ao medo etc, construindo consumidores passivos de uma cultura padronizada e elitista.

Os indivíduos deslocam-se pelo espaço urbano, habitam em seus bairros, nesse processo de produção e reprodução, consomem além de alimentos, aquilo que podemos chamar de meio de consumo coletivo, que é tudo aquilo que é utilizado em comum pela população, visando ao bem estar de todos, o que envolve uma infra-estrutura urbana com hospitais, escolas, saneamento, água e eletricidade, os meios de comunicação e as áreas de lazer. Cada comunidade procurará o que mais lhe convém em face das características locais, tanto de área e posição geográfica quanto das atividades da população e números de habitantes.

O espaço público é o espaço de convívio de todos. Deste modo, o espaço público se traduz num espaço de todos e de acesso a todas as pessoas, à circulação, expressão e discussão de seu uso, sendo vinculado e administrado pelos poderes públicos federal, municipal ou estadual. Já o espaço privado é aquele reservado à vida privada, familiar e pessoal. 
Como em todos os processos sociais, os aspectos econômicos são determinantes de relações de privilégios e exclusões. Para isso, as ações públicas estão concentradas nas áreas nobres das cidades, geralmente deixando ao abandono os bairros periféricos (os mais populosos), sendo evidenciada esta desigualdade na constatação, entre outros, dos equipamentos sociais de lazer.

O espaço público de lazer deve ser um espaço de dinâmica cultural, onde podemos vivenciar o lúdico. Ele também proporciona o descanso, o divertimento e o desenvolvimento das habilidades pessoais e sociais. Compreender o processo de humanização dos espaços é uma das preocupações dos profissionais de lazer, de setores da sociedade civil e dos urbanistas, especialmente os espaços destinados ao lazer na cidade que são fundamentais nesse processo e abrigam uma diversidade de práticas esportivas, manifestações culturais e lúdicas, dentre outras, tendo em vista que uma política de lazer articula várias dimensões como: o deslocamento, o trabalho, o local de moradia e o lazer.

No Brasil, como nos países subdesenvolvidos, vítimas da globalização neoliberal, o lazer apresenta uma estrutura complexa que mantém relações com outros aspectos da vida e da organização do homem na sociedade, intimamente relacionada com uma crise econômica profunda que faz com que os Direitos Econômicos e Sociais básicos do ser humano como saúde, moradia e trabalho, sejam acessíveis apenas para uma parcela da população. Com isso, o direito ao lazer ocupa um segundo plano nas políticas públicas.

\section{VIVENCIANDO O LAZER EM FELIPE CAMARÃO}

Fundada em 1599, Natal surgiu em torno da Fortaleza dos Reis Magos, tendo um desenvolvimento lento e inexpressivo durante o período colonial, crescendo de forma espontânea e sem qualquer planejamento.

Só há bem pouco tempo, no século XX é que temos o desenvolvimento de atividades econômicas na cidade, promovendo a elaboração de planos urbanísticos para organizar o parcelamento e ocupação do solo. Com a Segunda Guerra Mundial, a cidade sofreu grandes modificações, principalmente provocadas pela utilização do aeroporto de Parnamirim e do Porto de Natal como áreas militares estratégicas para os aliados. Nesta época, surgiram as ocupações de áreas periféricas e posteriormente loteamentos e conjuntos residenciais, sem maiores planejamentos urbanísticos que lhe orientassem esta expansão.

Felipe Camarão tem sua história associada ao Rio Potengi, quando no início do século XX, aproximadamente em 1920, constituía-se numa pequena comunidade de pescadores que habitavam a margem direita do rio, onde encontraram um peixe-boi morto e passaram a denominar a localidade de Sítio Peixe-Boi. Pertencente ao Português Manoel Machado, grande proprietário de terras da região, que ao falecer em 1962, deixou sua herança para sua esposa, uma mulher que até hoje povoa as lendas na região, a Viúva Machado. Como grande administradora, a viúva vendeu parte de suas terras ao Sr. Gerold Geppert, de origem alemã, mas naturalizado brasileiro, criando o loteamento Reforma, que deu origem ao bairro de Felipe Camarão.

Como cita Cavalcante e Lima (1995 p.18): 
"O loteamento Reforma, que deu origem ao bairro de Felipe Camarão, ocorreu desta maneira (sem planejamento). Situada às margens do Rio Potengi, distante do centro da cidade, a área foi loteada na década de 60 e somente incluída no perímetro urbano na década de 80".

Só em 22 de agosto de 1968, Felipe Camarão recebe o título de bairro, sendo na década de 80, incorporado à região metropolitana de Natal e passando, assim, a homenagear um importante chefe indígena do estado, o índio poti Felipe Camarão.

Com uma população de 45.907 habitantes e uma área de 663,40ha, divididos em 10.782 domicílios particulares, numa média de 69,20 habitantes por $\mathrm{km}^{2}$,Felipe Camarão é segundo dados do IBGE e do plano Diretor de Natal, um dos maiores e mais populosos da cidade, representando 4,5\% da população da cidade e 19,4\% da Região Oeste (área administrativa municipal que pertence).

Estigmatizado na mídia e no senso comum como um bairro violento e pobre, sofre discriminação e abandono por parte dos poderes públicos, é dividido internamente entre Camarão I e II, que se constituem em diversas localidades: Peixe-Boi, KM6, Baixa do Sagüi e Barreiros e dos conjuntos Felipe Camarão (PROMORAR), Jardim América, Vida Nova II e III e Lavadeiras, além das favelas: Alta Tensão, Palha, Maré, Barreiros, Torre, Fio, Alemão e Promorar.

Como cita Basílio (2004 p.46):

“Felipe Camarão possui três estabelecimentos na área de saúde, dez escolas públicas e seis particulares, quatro creches municipais e uma particular, mas, em seu cenário, segundo dados da SEMSUR (2001), não consta a existência de praças, fator que implica em infraestrutura que não leva em conta a preocupação com o lazer. Em uma comunidade grande, cheia de ruas e becos, de grandes expressões culturais como Manoel Marinheiro e Chico Daniel, seis organizações de representação comunitária, sem falar nos diversos grupos, expressões e organizações não governamentais, atuam na área.”

Como procedimento metodológico para a pesquisa dos equipamentos de lazer do Bairro de Felipe Camarão, realizada pelos alunos do Curso de Lazer e Qualidade de Vida do CEFET/RN, foram utilizados instrumentos de coleta de dados como questionários semiestruturados, roteiro de observação, entrevistas gravadas e registro fotográfico. A população alvo foram os freqüentadores que visitam "os equipamentos de lazer do bairro" no seu tempo livre e os segmentos representativos do bairro, como lideranças comunitárias, esportistas, etc.

Constatamos, além do que reproduzimos acima, uma completa ausência de equipamentos públicos de lazer na comunidade, e apenas duas quadras esportivas existentes, completamente abandonadas e sem manutenção, sem falar da total ausência de apoio e incentivo à promoção de atividades com a comunidade.

Este completo abandono é contrastado com o vigor, garra e dedicação de diversos moradores do bairro, que, de forma voluntária, desenvolvem escolinhas de futebol com as 
crianças e jovens do bairro, atividades de capoeira, quadrilhas juninas e outras atividades esportivas e culturais, demonstrando a resistência e força de realização de pessoas que acreditam que fazem a diferença.

A prática de lazer predominante no bairro é o futebol, presença constante em todas as esquinas, em cima das dunas (um espaço concreto de lazer na região), e nos terrenos baldios inclusive em uma área crítica utilizada pela comunidade que é a região onde passam as redes de alta tensão da CHESf, um espaço utilizado para a realização de partidas de futebol, lixão e ocupação de favelas. Como afirma um morador entrevistado, que vive em Camarão há mais de 20 anos, Sr. Assis Borges “Aqui não tem cuidado de nada, aqui não existe isso. Aqui tem um vereador do bairro que só puxa pra ele, pra outra coisa aqui eu não vejo beneficio nenhum.”

Durante as visitas ao bairro, constatou-se a total inexistência de praças e áreas públicas para a comunidade. Foram localizados três espaços públicos destinados à construção de praças, no entanto, nenhum tem qualquer construção, servindo apenas para a acumulação de lixo e mato.

A Empresa de ônibus Conceição está finalizando a construção de um campo/mini-estádio de futebol para a comunidade, que será beneficiada com um espaço profissional, contando inclusive com refletores, grama, vestiários e arquibancada, mas este espaço foi negociado como pagamento em troca de um terreno que a empresa utilizará, destruindo o campo atual para ampliar sua garagem. O que nos parece é que o novo espaço, pelas suas características e infra-estrutura, será destinado aos poucos privilegiados do bairro, que participam dos clubes amadores, não sendo prevista ou articulada qualquer ação ou atividades com jovens e crianças de Felipe Camarão.

\section{PENSANDO UM FUTURO, COM LAZER E QUALIDADE DE VIDA}

A pesquisa das vivências e convivências de lazer no Bairro de Felipe Camarão foi de grande importância, por se tratar de um assunto pouco explorado e que pode servir de subsídio para formulação de políticas públicas de lazer no bairro estudado, como também fornecer dados concretos sobre a situação atual dos equipamentos públicos de lazer de Felipe Camarão.

Nos bairros periféricos de Natal, como nas cidades de um modo geral, esta realidade encontra-se envolvida em diversos problemas sociais, econômicos, políticos e culturais, apresentando para a população desses bairros dificuldades concretas para a vivência do lazer e promoção da qualidade de vida.

Felipe Camarão vive um completo abandono de espaços e ações afirmativas, capazes de promover o lazer e a qualidade de vida para a sua população, que recorre a suas próprias habilidades e ações voluntárias para promover ações neste sentido, revelando o completo abandono dos poderes públicos constituídos.

A atuação da comunidade e suas organizações de base, no sentido de pressionar e exigir a presença do poder público, bem como a atuação de profissionais de lazer e urbanismo, comprometidos com a construção de uma cidade includente e viva, capaz de proporcionar espaços interativos e plurais para a comunidade, são as bases para pensarmos e afirmarmos que um outro mundo, justo e fraterno é possível. 
Sente-se que Felipe Camarão possui potencialidades sociais e culturais capazes de, com apoio do poder público, promover o lazer no bairro.

\section{REFERÊNCIAS BIBLIOGRAFICAS}

BASÍLIO, Maria Divaneide. Ação coletiva e reinvenção do cotidiano: O Caso de Felipe Camarão, Monografia (Curso de Ciências Sociais) - Universidade Federal do rio Grande do Norte, Natal, 2004.

BRUHNS, Heloísa Turini. Introdução aos estudos do lazer. Campinas, SP: Editora da UNICAMP, 1997.

CAVALCANTE, Eunádia; LIMA, Verônica. Construindo o seu Lugar. RN: Editora da UFRN, 1995.

DUMAZEDIER, Jofre. Sociologia empírica do lazer. São Paulo: Perspectiva, 1979.

GIL, Antônio Carlos. Como elaborar projetos de pesquisa. $3^{\text {a }}$. Ed. São Paulo: Atlas, 1991.

LIMA, Dália M. M. C. de. Nos caminhos do lazer: A Infra-estrutura urbana e o espaço do lazer Norte Riograndense. Natal, RN: edição independente, 2002.

Passando por Pium: A Influência do lazer e do turismo no litoral oriental do Rio Grande do Norte. Natal, RN: edição independente, 2001.

MARCELlinO, Nelson Carvalho. Políticas Públicas Setoriais de Lazer: o papel das prefeituras. Campinas, Papirus, 1987.

TURINO, Célio. Lazer nos programas sociais: Propostas de combate à violência e à exclusão. São Paulo. Anita, 2003. 